\title{
Prognostic significance of adjuvant radiation therapy in adenocarcinoma of the cecum
}

\author{
Sare Hosseini, MD', Ali Mohammad Bananzadeh, MD², Mohammad Mohammadianpanah, MD², \\ Roham Salek, MD¹, Ali Taghizadeh-Kermani, MD \\ ${ }^{1}$ Cancer Research Center, Faculty of Medicine, Mashhad University of Medical Sciences, Mashhad; \\ ${ }^{2}$ Colorectal Research Center, Department of Radiation Oncology, Shiraz University of Medical Sciences, Shiraz, Iran
}

Purpose: Local recurrence is a common failure pattern in adenocarcinoma of the cecum. This study aimed to investigate the potential role of adjuvant radiation therapy on oncologic outcomes of patients with adenocarcinoma of the cecum.

Materials and Methods: This retrospective study was carried out at three large tertiary university hospitals. We analyzed the characteristics, prognostic factors, and survival of 162 patients with adenocarcinoma of the cecum that were treated and followed up between 2000 and 2013. All the patients had undergone a right hemicolectomy and received chemotherapy with $(n=48)$ or without $(n=114)$ adjuvant radiation therapy.

Results: The subjects were 65 females and 97 males with a median age of 56 years (range, 17 to 90 years) at diagnosis. The 5-year local control (LC), disease free survival (DFS), and overall survival (OS) rates were $72.7 \%, 57.2 \%$, and $62.6 \%$ respectively. In a multivariate analysis, age, tumor stage, node stage, and adjuvant radiation therapy were determined to be independent prognostic factors. Age more than 55 years (hazard ratio $[H R]=1.0 ; 95 \%$ confidence interval $[\mathrm{Cl}], 0.06-0.32 ; p=0.003)$, T4 stage $(H R=$ $6.8 ; 95 \% \mathrm{Cl}, 3.07-15.36 ; \mathrm{p}<0.001)$, node positive disease ( $\mathrm{HR}=4.2 ; 95 \% \mathrm{Cl}, 1.94-9.13 ; \mathrm{p}<0.001)$, and the absence of adjuvant radiation therapy $(\mathrm{HR}=3.0 ; 95 \% \mathrm{Cl}, 1.39-6.46 ; \mathrm{p}=0.005)$ had a negative influence on $\mathrm{OS}$.

Conclusion: Adjuvant radiation therapy significantly improves DFS and OS in patients with adenocarcinoma of the cecum.

Keywords: Adenocarcinoma, Cecum, Colon, Adjuvant radiation therapy, Prognosis

\section{Introduction}

Colon cancer is the third most common cancer in the world [1]. Right sided tumors, including those of the cecum, ascending and transverse colons, comprise $40 \%$ of colorectal cancers in high incidence areas $[2,3]$. Locoregional recurrence is a common pattern of failure in advanced adenocarcinoma of the cecum $[4,5]$. Although external beam radiation has gained widespread acceptance for reducing local recurrence in rectal cancer [6,7], the role of adjuvant radiotherapy in colon cancer is unknown. The possible causes for infrequent use of radiotherapy in the treatment of high risk colon cancer are the lack of robust evidence of the potential role of radiotherapy as well as technical issues related to the irradiation of the upper abdomen associated with small bowel toxicity [8]. However, there are reports, which have proved the beneficial effect of

Received 18 June 2017, Revised 09 September 2017, Accepted 11 October 2017.

Correspondence: Mohammad Mohammadianpanah, MD, Colorectal Research Center, Department of Radiation Oncology, Shiraz University of Medical Sciences, Shiraz 71936, Iran. Tel: +98-71-36125170, Fax: +98-71-36474320, E-mail: mohpanah@gmail.com; mohpanah@sums.ac.ir

(c) This is an Open Access article distributed under the terms of the Creative Commons Attribution Non-Commercial License (http://creativecommons.org/ licenses/by-nc/4.0/) which permits unrestricted non-commercial use, distribution, and reproduction in any medium, provided the original work is properly cited.

www.e-roj.org 


\section{Sare Hosseini, et al}

adjuvant radiotherapy on the survival of patients with locally advanced carcinoma of the cecum $[9,10]$.

The current study was designed to evaluate the potential role of postoperative radiotherapy in the management of adenocarcinoma of the cecum.

\section{Materials and Methods}

The present retrospective study was performed at three tertiary academic hospitals. We analyzed the characteristics, prognostic factors, and survival of patients with adenocarcinoma of the cecum who had been treated and followed up between January 2000 and December 2013. The study was approved by the Clinical Research Ethics Committee of Shiraz University of Medical Sciences (No. CT-P-93-7219) in accordance with the code of ethics of the World Medical Association (Declaration of Helsinki) for experiments involving humans. The median follow-up was 58 months for surviving patients. In this study, tumor location was defined as cecum according to the findings of colonoscopy, CT scan images, surgeon note and pathologic report. In this study, large lesions mainly located in the cecum with involvement of adjacent structures such as ileum or ascending colon, were considered as primary cecal cancer. However, patients with double primary colorectal cancer or multicentric tumors were excluded. Tumor staging was performed using the seventh edition of the American Joint Committee on Cancer TNM staging system [11]. Preliminary evaluation included a comprehensive history and physical examination, colonoscopy, complete blood cell count (CBC), liver and renal function studies, a carcinoembryonic antigen (CEA), and chest, abdominal and pelvic CT scans. Indication of adjuvant radiation therapy was defined based on physician's choice and it was considered for T3-T4 and/or node positive cases.

\section{External beam chemoradiation}

The concurrent adjuvant chemoradiation consisted of external beam radiation therapy (EBRT) and chemotherapy (bolus 5-fluorouracil [5-FU]/leucovorin or capecitabine monotherapy) was started 4 to 6 weeks after surgery and using megavoltage linear accelerator photons. The photon energy was 15-18 $\mathrm{MV}$ in a two-field (anteroposterior and posteroanterior [APPA] parallel opposed fields) or multiple field technique. Preoperative CT scan images was used to design radiation fields. A median dose of $45 \mathrm{~Gy}$ (range, 45 to $50.4 \mathrm{~Gy}$ ) with a daily fraction of 1.8-2 Gy at 5 fractions per week was delivered to the right iliac fossa. In addition to tumor bed, right external

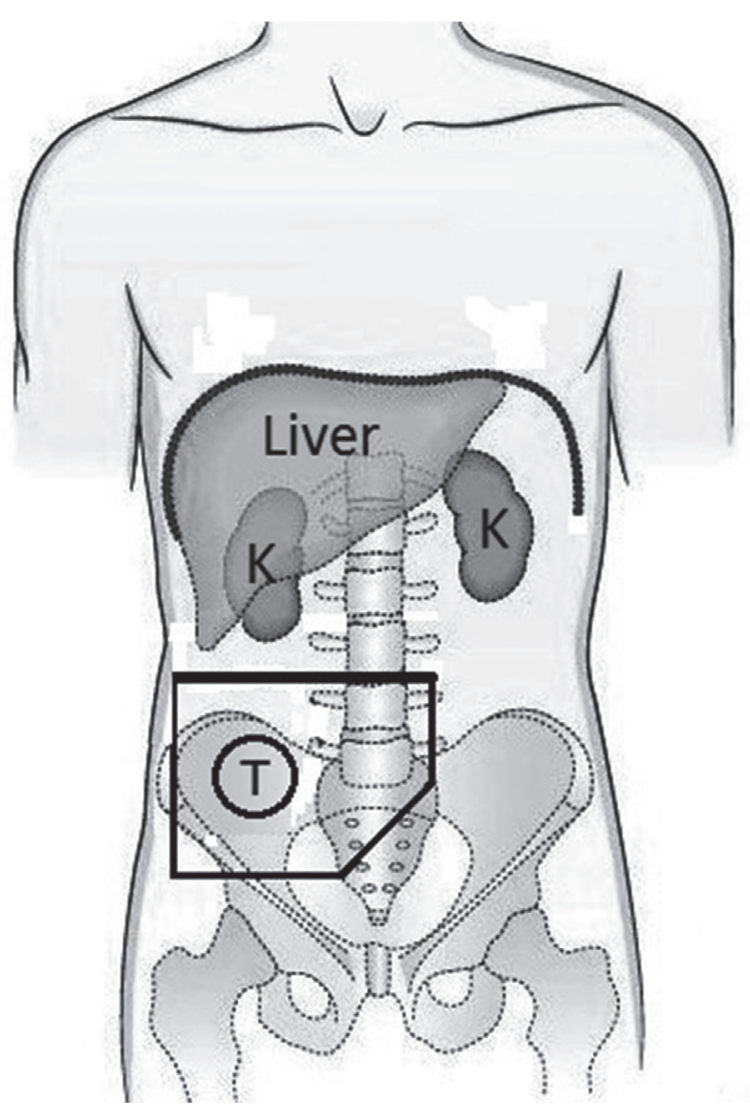

Fig. 1. Schematic postoperative anteroposterior-posteroanterior radiation portals including tumor bed and nodal regions of cecal cancer.

and common iliac nodes were included in T4 disease. Fig. 1 illustrates a schematic postoperative anteroposteriorposteroanterior (AP-PA) radiation portal including tumor bed and nodal regions of cecal cancer. The primary tumor bed was covered with a 4- to 5-cm margin proximally and distally and with a 3- to 4-cm margin laterally and medially covering areas of potential residual disease. Organ at risk such as kidneys, liver, spinal cord and small bowel were excluded as much as possible.

\section{Chemotherapy}

Chemotherapy consisted of intravenous bolus 5-FU $425 \mathrm{mg} /$ $\mathrm{m}^{2} /$ day and leucovorin $20 \mathrm{mg} / \mathrm{m}^{2} /$ day on days $1-5$ of every 3 -week cycle, or monotherapy with oral capecitabine 825 $\mathrm{mg} / \mathrm{m}^{2}$ twice daily for 14 days of every 3 -week cycle, or capecitabine $1,000 \mathrm{mg} / \mathrm{m}^{2}$ twice daily for 14 days of every 3-week cycle plus oxaliplatin $130 \mathrm{mg} / \mathrm{m}^{2}$ intravenously on day 1 (Cape0x regimen); or oxaliplatin $85 \mathrm{mg} / \mathrm{m}^{2}$ on day 1 , plus a 2-hour infusional leucovorin $200 \mathrm{mg} / \mathrm{m}^{2}$ on days 1 and 2 , 


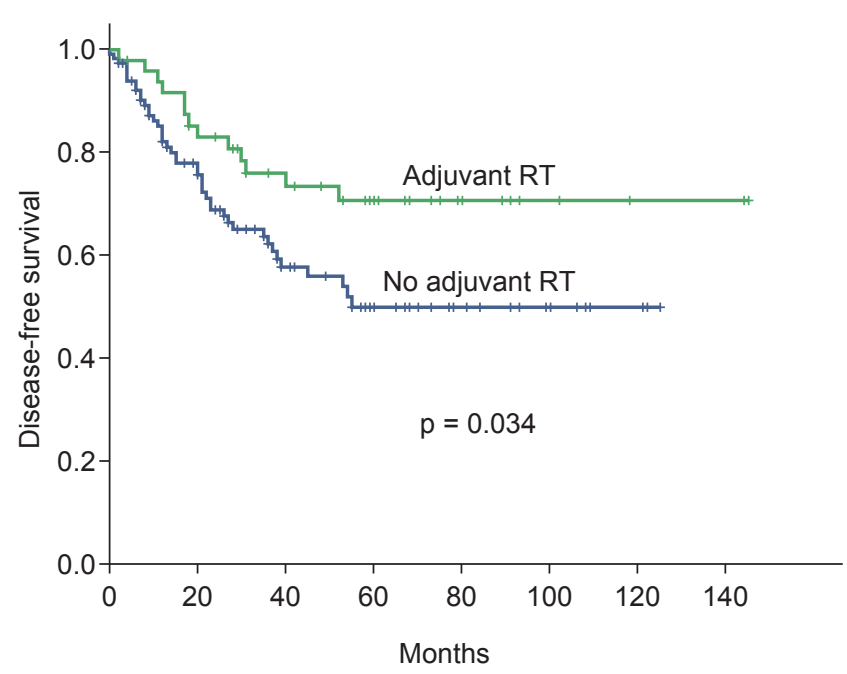

Fig. 2. Kaplan-Meier survival curves for disease-free survival categorized according to adjuvant radiation therapy (RT).

followed by bolus 5 -FU $400 \mathrm{mg} / \mathrm{m}^{2}$ and then 5 -FU $600 \mathrm{mg} /$ $\mathrm{m}^{2}$ over a 22-hour infusion on days 1 and 2, every 2 weeks (FOLFOX regimen). Additionally, bolus 5-FU/leucovorin (before 2010) or capecitabine monotherapy (since 2010) was employed for concurrent chemotherapy in cases receiving adjuvant chemoradiation.

\section{Statistics}

Clinical and pathological variables were analyzed by IBM SPSS Statistics software version 22 (IBM, Armonk, NY, USA). Categorical variables of patient demographics (such as sex and categorized age), tumor characteristics (such as stage, grade, surgical marine status, lymphatic vascular invasion, perineural invasion, and categorized tumor size), and treatment modalities (such as adjuvant radiotherapy) were compared by using chisquare tests; for continuous variables, such as patient age and tumor size, Student t-tests were employed. Proportions were compared with Fisher exact test for unordered or ordered categorical variables. Univariate analyses for local control (LC), disease-free survival (DFS), and overall survival (OS) rates were carried out using the Kaplan-Meier method and prognostic factors were compared by log-rank test. A multiple-covariate analysis was performed with the stepwise regression hazards model. Potential variables with a p-value less than 0.2 in univariate analysis were entered the multivariate regression model. The hazard ratio (HR) for death, with a 95\% confidence interval $(\mathrm{Cl})$, was calculated for the variable groups. The logrank test compared treatment results in each variable group.

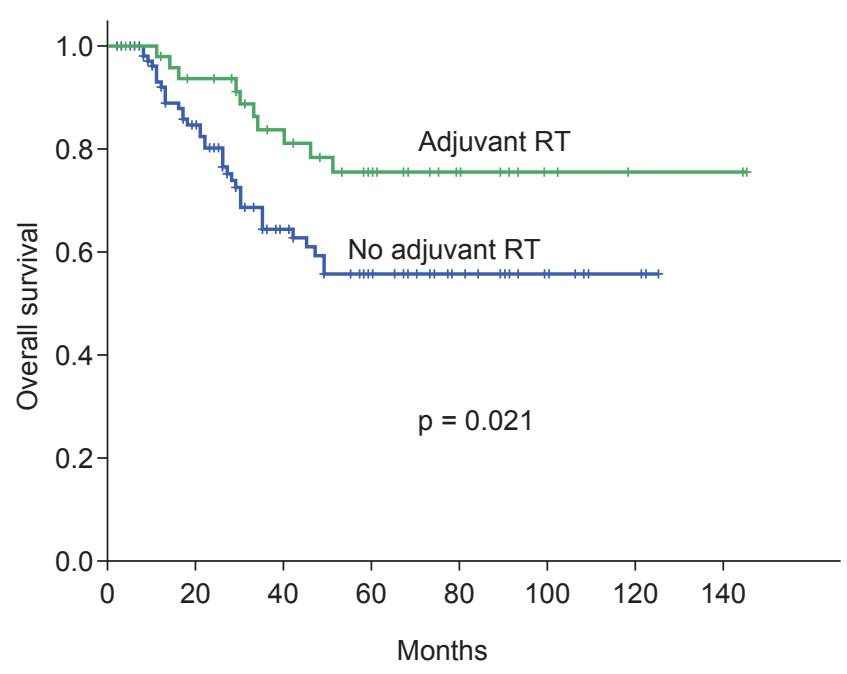

Fig. 3. Kaplan-Meier survival curves for overall survival categorized according to adjuvant radiation therapy (RT).

All statistical tests were two-sided and p-values less than 0.05 were considered significant.

\section{Results}

\section{Age and sex}

The subjects were 65 females and 97 males ranging from 17 to 90 years, with a median age of 56 years at diagnosis for all patients. A peak frequency was observed between the sixth and seventh decade of life in both genders.

\section{Treatment}

All the patients had undergone a curative surgery as right hemicolectomy. Surgical margin was free in 156 (96\%) and involved in $6(4 \%)$ cases. All patients received chemotherapy with $(n=48)$ or without ( $n=114$ ) adjuvant radiation therapy. There was a significant difference regarding oxaliplatin based chemotherapy used in stage III compared to stage II (82\% vs. $34 \%, p<0.001)$; however, the distribution of oxaliplatin based chemotherapy regarding adjuvant radiation was not significantly different (Table 1).

\section{Tumor characteristics}

One hundred and one patients (62\%) had stage II disease and 61 (38\%) had stage III. The distribution of most clinical and pathological characteristics were not significantly different between the patients receiving and not receiving adjuvant radiation; however, tumor size was significantly larger ( $p=$ 
Table 1. Clinical and pathological characteristics of 162 patients with adenocarcinoma of the cecum

\begin{tabular}{|c|c|c|c|}
\hline \multirow{2}{*}{ Variable } & \multicolumn{2}{|c|}{ Adjuvant RT } & \multirow{2}{*}{ p-value } \\
\hline & Received & Not received & \\
\hline Total & $48(30)$ & $114(70)$ & \\
\hline Sex & & & 0.927 \\
\hline Male & $29(60)$ & $68(60)$ & \\
\hline Female & $19(40)$ & $46(40)$ & \\
\hline Age (yr) & $55.5 \pm 11.8$ & $55.4 \pm 15.6$ & 0.982 \\
\hline Tumor size & $6.3 \pm 2.8$ & $5.5 \pm 2.0$ & 0.033 \\
\hline Tumor stage & & & 0.287 \\
\hline $\mathrm{T} 2$ & $3(6)$ & $4(4)$ & \\
\hline T3 & $42(88)$ & $94(82)$ & \\
\hline $\mathrm{T} 4$ & $3(6)$ & $16(14)$ & \\
\hline Node stage & & & 0.107 \\
\hline No & $34(71)$ & $67(59)$ & \\
\hline N1 & $8(17)$ & $35(31)$ & \\
\hline N2 & $6(12)$ & $12(10)$ & \\
\hline Dissected LN & $11.5 \pm 9.8$ & $11.4 \pm 7.7$ & 0.936 \\
\hline Involved node & $2.0 \pm 6.3$ & $1.2 \pm 2.5$ & 0.250 \\
\hline Surgical margin status & & & 0.671 \\
\hline Free & $47(98)$ & $109(96)$ & \\
\hline Involved & $1(2)$ & $5(4)$ & \\
\hline Disease stage & & & 0.135 \\
\hline Stage II & $34(71)$ & $67(59)$ & \\
\hline Stage III & $14(29)$ & $47(41)$ & \\
\hline Tumor grade & & & 0.153 \\
\hline I & $25(52)$ & $62(55)$ & \\
\hline$\|$ & $15(31)$ & $46(40)$ & \\
\hline III & $8(17)$ & $6(5)$ & \\
\hline Lymphatic-vascular invasion & & & 0.021 \\
\hline Present & $20(42)$ & $27(24)$ & \\
\hline Not present & $28(58)$ & $87(76)$ & \\
\hline Perineural invasion & & & 0.350 \\
\hline Present & $11(23)$ & $19(17)$ & \\
\hline Not present & $37(77)$ & $95(83)$ & \\
\hline Chemotherapy regimen & & & 0.392 \\
\hline Oxaliplatin based & $23(48)$ & $63(55)$ & \\
\hline Others & $25(52)$ & $51(45)$ & \\
\hline
\end{tabular}

Values are presented as number (\%) or mean \pm standard deviation. $\mathrm{RT}$, radiotherapy; LN, lymph node.

0.033) and with more frequent lymphatic-vascular invasion in patients receiving adjuvant radiation $(p=0.021)$. Table 1 represents and compares the distribution of patients and tumor clinical characteristics in terms of adjuvant radiation.

\section{Chemoradiation-related toxicity}

Acute gastrointestinal toxicity as diarrhea and abdominal pain was the most frequent complication in patients receiving adjuvant chemoradiation. Most patients $(n=26)$ developed grade I (35\%), grade II (13\%) or grade III (6\%) diarrhea. All the patients tolerated well gastrointestinal toxicity with supportive care and without chemoradiation interruption. As well, gastrointestinal complaints were the most common late morbidity among all the patients. Forty-six patients in irradiated $(n=17)$ and non-irradiated $(n=29)$ group complained only grade I small or large intestinal toxicity during the first and the second year of treatment. No patients developed grade II or higher late toxicity. We did not find a statistical difference for acute $(p=0.230)$ or late $(p=0.534)$ toxicity rate in radiation group compared with non-irradiated 
Table 2. Univariate analysis of prognostic factors for 5 -year LC rate in 162 patients with adenocarcinoma of the cecum

\begin{tabular}{|c|c|c|c|}
\hline Variable & $5-y r$ LC (\%) & p-value & HR (95\% Cl) \\
\hline Sex & & 0.287 & $1.536(0.69-2.38)$ \\
\hline Male & 68.7 & & \\
\hline Female & 78.6 & & \\
\hline Age (yr) & & 0.361 & $0.701(0.32-1.50)$ \\
\hline$<55$ & 72.8 & & \\
\hline$\geq 55$ & 73.4 & & \\
\hline Tumor size (cm) & & 0.041 & $0.442(0.20-0.96)$ \\
\hline$\leq 5$ & 75.1 & & \\
\hline$>5$ & 68.2 & & \\
\hline Tumor stage & & 0.008 & $0.197(0.06-0.65)$ \\
\hline $\mathrm{T} 2-3$ & 75.1 & & \\
\hline $\mathrm{T} 4$ & 39.2 & & \\
\hline Node stage & & 0.099 & $0.257(0.05-1.29)$ \\
\hline No & 73.1 & & \\
\hline N1-2 & 52.5 & & \\
\hline Dissected LN & & 0.857 & $0.928(0.41-2.09)$ \\
\hline$\leq 9$ & 71.1 & & \\
\hline$>9$ & 73.3 & & \\
\hline Involved node & & 0.126 & $4.237(0.66-25.53)$ \\
\hline$\leq 2$ LNs & 70.9 & & \\
\hline$>2$ LNs & 78.6 & & \\
\hline Disease stage & & 0.479 & $1.416(0.54-3.69)$ \\
\hline$\|$ & 71.7 & & \\
\hline III & 74.1 & & \\
\hline Tumor grade & & 0.140 & $1.806(0.82-3.95)$ \\
\hline I & 70.0 & & \\
\hline II-III & 75.5 & & \\
\hline Surgical margin & & 0.457 & $1.862(0.36-9.60)$ \\
\hline Involved & 62.5 & & \\
\hline Free & 73.0 & & \\
\hline Lymphatic-vascular invasion & & 0.080 & $0.445(0.18-1.10)$ \\
\hline Present & 58.1 & & \\
\hline Not present & 78.2 & & \\
\hline \multicolumn{4}{|l|}{ Perineural invasion } \\
\hline Present & 58.9 & & \\
\hline Not present & 78.1 & 0.820 & $1.132(0.38-3.30)$ \\
\hline Adjuvant RT & & 0.173 & $1.806(0.77-4.22)$ \\
\hline Received & 78.8 & & \\
\hline Not received & 68.8 & & \\
\hline Chemotherapy regimen & & 0.810 & $1.08(0.54-2.18)$ \\
\hline Oxaliplatin based & 76.3 & & \\
\hline Others & 70.7 & & \\
\hline
\end{tabular}

LC, local control; HR, hazard ratio; $\mathrm{Cl}$, confidence interval; LN, lymph node; RT, radiotherapy.

group. Additionally, there was no statistical difference regarding the rate of acute $(p=0.809)$ and late $(p=0.738)$ gastrointestinal toxicity regarding radiotherapy technique.

\section{Survival rates and prognostic factors}

A median follow-up of 58 months for the original subjects reported that, 106 patients were alive and without disease, 10 patients were alive with disease, and 46 patients had died due to disease. The 5-year LC rate was $72.7 \%$. In the univariate analysis, the tumor stage $(p=0.008)$, and tumor size ( $p=$ 0.041) were found to be prognostic factors for LC. From the multivariate analysis, only the tumor stage was determined to 
Table 3. Univariate analysis of prognostic factors for 5-year DFS rate in 162 patients with adenocarcinoma of the cecum

\begin{tabular}{|c|c|c|c|}
\hline Variable & $5-y r$ DFS (\%) & $p$-value & HR (95\% Cl) \\
\hline Sex & & 0.156 & $1.56(0.84-2.91)$ \\
\hline Male & 51.2 & & \\
\hline Female & 66.7 & & \\
\hline Age (yr) & & 0.202 & $1.02(0.98-1.06)$ \\
\hline$<55$ & 61.4 & & \\
\hline$\geq 55$ & 54.3 & & \\
\hline Tumor size (cm) & & 0.400 & $1.08(0.89-1.32)$ \\
\hline$\leq 5$ & 50.3 & & \\
\hline$>5$ & 61.6 & & \\
\hline Tumor stage & & 0.002 & $0.22(0.08-0.58)$ \\
\hline T2-3 & 60.7 & & \\
\hline T4 & 20.3 & & \\
\hline Node stage & & 0.002 & $0.18(0.06-0.55)$ \\
\hline No & 60.2 & & \\
\hline N1-2 & 25.2 & & \\
\hline Dissected LN & & 0.715 & $0.99(0.93-1.04)$ \\
\hline$\leq 9$ & 53.3 & & \\
\hline$>9$ & 59.8 & & \\
\hline Involved node & & 0.382 & $1.04(0.95-1.14)$ \\
\hline$\leq 2$ LNs & 57.8 & & \\
\hline$>2$ LNs & 47.7 & & \\
\hline Disease stage & & 0.659 & $1.18(0.55-2.52)$ \\
\hline II & 62.7 & & \\
\hline III & 48.9 & & \\
\hline Tumor grade & & 0.580 & $1.19(0.64-2.19)$ \\
\hline 1 & 56.3 & & \\
\hline II-III & 58.5 & & \\
\hline Surgical margin & & 0.229 & $2.62(0.54-12.69)$ \\
\hline Involved & 62.5 & & \\
\hline Free & 57.0 & & \\
\hline Lymphatic-vascular invasion & & 0.021 & $0.42(0.20-0.88)$ \\
\hline Present & 39.4 & & \\
\hline Not present & 65.1 & & \\
\hline Perineural invasion & & 0.718 & $1.17(0.49-1.79)$ \\
\hline Present & 38.8 & & \\
\hline Not present & 62.5 & & \\
\hline Adjuvant RT & & 0.034 & $2.90(1.40-6.03)$ \\
\hline Received & 70.6 & & \\
\hline Not received & 49.9 & & \\
\hline Chemotherapy regimen & & 0.510 & $0.83(0.49-1.42)$ \\
\hline Oxaliplatin based & 56.7 & & \\
\hline Others & 59.1 & & \\
\hline
\end{tabular}

DFS, disease-free survival; HR, hazard ratio; $\mathrm{Cl}$, confidence interval; LN, lymph node; $\mathrm{RT}$, radiotherapy.

be independent prognostic factors for local control. T4 disease $(\mathrm{HR}=0.30 ; 95 \% \mathrm{Cl}, 0.12-0.75 ; \mathrm{p}=0.010)$ had a negative influence on LC (Table 2).

The 5-year DFS rates were 57.2\%. In the univariate analysis, the tumor stage $(p=0.002)$, node stage $(p=0.002)$, lymphaticvascular invasion $(p=0.021)$, and adjuvant radiation ( $p=$
0.034) were found to be prognostic factors for DFS (Fig. 2). From the multivariate analysis, the tumor stage, node stage, lymphatic-vascular invasion, and adjuvant radiation therapy were determined to be independent prognostic factors. T4 disease $(H R=0.30 ; 95 \% \mathrm{Cl}, 0.15-0.62 ; p=0.001)$, higher node stage $(H R=0.31 ; 95 \% C l, 0.15-0.64 ; p=0.002)$, the presence 
Table 4. Univariate analysis of prognostic factors for 5-year OS rate in 162 patients with adenocarcinoma of the cecum

\begin{tabular}{|c|c|c|c|}
\hline Variable & $5-y r$ OS (\%) & $p$-value & HR $(95 \% \mathrm{Cl})$ \\
\hline Sex & & 0.366 & $1.34(0.69-2.59)$ \\
\hline Male & 59.8 & & \\
\hline Female & 66.7 & & \\
\hline Age (yr) & & 0.002 & $1.03(1.01-1.05)$ \\
\hline$<55$ & 69.3 & & \\
\hline$\geq 55$ & 57.3 & & \\
\hline Tumor size (cm) & & 0.272 & $1.08(0.94-1.24)$ \\
\hline$\leq 5$ & 58.7 & & \\
\hline$>5$ & 65.4 & & \\
\hline Tumor stage & & $<0.001$ & $0.15(0.05-0.39)$ \\
\hline T2-3 & 67.2 & & \\
\hline $\mathrm{T} 4$ & 17.8 & & \\
\hline Node stage & & $<0.001$ & $0.13(0.04-0.39)$ \\
\hline No & 67.1 & & \\
\hline N1-2 & 23.0 & & \\
\hline Dissected LN & & 0.267 & $0.97(0.93-1.01)$ \\
\hline$\leq 9$ & 61.6 & & \\
\hline$>9$ & 62.4 & & \\
\hline Involved node & & 0.163 & $1.07(0.97-1.18)$ \\
\hline$\leq 2$ LNs & 64.9 & & \\
\hline$>2$ LNs & 43.0 & & \\
\hline Disease stage & & 0.091 & $2.11(0.88-5.05)$ \\
\hline II & 66.7 & & \\
\hline III & 55.3 & & \\
\hline Tumor grade & & 0.607 & $0.84(0.43-1.61)$ \\
\hline I & 65.7 & & \\
\hline$\|-I\|$ & 58.6 & & \\
\hline Surgical margin & & 0.065 & $7.68(0.88-67.16)$ \\
\hline Involved & 62.1 & & \\
\hline Free & 75.0 & & \\
\hline Lymphatic-vascular invasion & & 0.015 & $2.73(1.21-6.17)$ \\
\hline Present & 44.0 & & \\
\hline Not present & 71.5 & & \\
\hline Perineural invasion & & 0.285 & $1.73(0.63-4.79)$ \\
\hline Present & 45.5 & & \\
\hline Not present & 68.1 & & \\
\hline Adjuvant RT & & 0.021 & $4.09(1.80-9.31)$ \\
\hline Received & 75.5 & & \\
\hline Not received & 55.8 & & \\
\hline Chemotherapy regimen & & 0.409 & $0.78(0.43-1.40)$ \\
\hline Oxaliplatin based & 60.0 & & \\
\hline Others & 65.9 & & \\
\hline
\end{tabular}

OS, overall survival; HR, hazard ratio; $\mathrm{Cl}$, confidence interval; LN, lymph node; RT, radiotherapy.

of lymphatic-vascular invasion $(\mathrm{HR}=0.49 ; 95 \% \mathrm{Cl}, 0.28-0.85$; $\mathrm{p}=0.012$ ), and the absence of adjuvant radiation therapy (HR $=2.50 ; 95 \% \mathrm{Cl}, 1.29-4.84 ; p=0.006$ ) had a negative influence on DFS (Table 3).

The 5-year OS rates were $62.6 \%$. In the univariate analysis, age $(p=0.002)$, tumor stage $(p<0.001)$, node stage $(p<$
0.001), Iymphatic-vascular invasion ( $p=0.015)$, and adjuvant radiation ( $p=0.021$ ) were found to be prognostic factors for OS. From the multivariate analysis, age, tumor stage, node stage and adjuvant radiation therapy were determined to be independent prognostic factors (Fig. 3). Age more than 55 years $(H R=1.0 ; 95 \% C l, 0.06-0.32 ; p=0.003)$, T4 stage $(H R$ 
$=6.8 ; 95 \% \mathrm{Cl}, 3.07-15.36 ; \mathrm{p}<0.001)$, node positive disease $(\mathrm{HR}=4.2 ; 95 \% \mathrm{Cl}, 1.94-9.13 ; \mathrm{p}<0.001)$, and the absence of adjuvant radiation therapy $(\mathrm{HR}=3.0 ; 95 \% \mathrm{Cl}, 1.39-6.46 ; \mathrm{p}=$ 0.005) had a negative influence on OS (Table 4).

\section{Discussion and Conclusion}

The results of the present study revealed the predominance of cecum adenocarcinoma among males, while tumor presentation at an old age was common in both genders. Although local control was not affected by radiotherapy, adjuvant radiation significantly improved the patient's DFS and OS.

Right sided colon cancers usually present among the elderly and many believe that they have more advanced stage at the time of diagnosis [12-14]. In contrast to our findings, the proportion of female patients with cecum adenocarcinoma was higher in several other studies $[4,15,16]$. As a dominant pattern of recurrence, locoregional failure has strengthened the argument that adjuvant radiotherapy might enhance the local control of this cancer. Several retrospective studies, especially those before 1995, have shown the improvement of local control and overall survival when adjuvant radiotherapy was employed for advanced colon cancer [17-19].

Among the studies on adjuvant radiotherapy, Shehata et al. [9] specifically addressed cecum adenocarcinoma. A significant reduction in the local recurrence rate (3\%) and improvement in 5-year DFS was recorded for those patients with lymph node metastasis who had received adjuvant radiotherapy as opposed to surgery alone. Niloofar et al. [20] reported the results of 65 patients with high risk colorectal cancer (which four were in the cecum) in 2005, who had been treated with postoperative chemotherapy with 5 - FU versus chemoradiation. Adjuvant radiotherapy did not improve local control and treatment-related complications in the chemoradiation group were substantial. In this study, we found a non-significant trend ( $p=0.173$ ) for better local control in cases receiving adjuvant radiation. This is most probably due to either underdiagnosis or under recording of a local failure in the context of metastatic or disseminated disease. A small local recurrent disease may be easily missed or ignored in this setting and not recorded.

The single prospective trial (Intergroup-0130), which had been designed to assess the role of adjuvant chemoradiation in locally advanced colon cancer, was ended prematurely due to low accrual [21]. Although whole abdominal radiation has been used in some studies [22-24], the radiotherapy technique in the majority of reported series has been two-dimensional, as two parallel opposed anteroposterior fields were employed $[9,17,20]$. These simple treatment plans could not spare the small bowel, which is main cause of treatment-related toxicity in abdominal radiation. In the modern era of radiotherapy, three-dimensional conformal radiotherapy (3DCRT) and intensity-modulated radiotherapy (IMRT) may provide the possibility of less toxic treatment. Apart from radiation toxicity, the emergence of more effective chemotherapy drugs has further shifted attention from adjuvant radiation; such chemotherapy agents include oxaliplatin which has produced profound improvement in the survival outcome of patients with stage II and III colon cancer [25-27]. It should be noted that $83 \%$ of patients in this study had locally advanced $(\mathrm{T} 3, \mathrm{~T} 4)$ tumors. According to most studies, the benefit of radiotherapy is more pronounced in patients with high stage tumors $[5,9,27]$.

The strength of the current study lies in its exclusive focus on cecum adenocarcinoma, which, according to the pattern of recurrence, may differ from the left side of the colon. We also evaluated the role of radiotherapy in the context of employing oxaliplatin-based chemotherapy. However, it should be noted that treatment-related toxicities were not assessed in the present study.

Future randomized prospective trials are needed to determine any potential benefit for adjuvant radiotherapy in the adenocarcinoma of the cecum.

In conclusion, adjuvant radiotherapy improves DFS and OS in locally advanced adenocarcinoma of the cecum, even in those patients receiving modern chemotherapy agents.

\section{Conflict of Interest}

No potential conflict of interest relevant to this article was reported.

\section{References}

1. Ferlay J, Soerjomataram I, Dikshit $R$, et al. Cancer incidence and mortality worldwide: sources, methods and major patterns in GLOBOCAN 2012. Int J Cancer 2015;136:E359-86.

2. Haenszel W, Correa P. Cancer of the large intestine: epidemiologic findings. Dis Colon Rectum 1973;16:371-7.

3. lacopetta B. Are there two sides to colorectal cancer? Int J Cancer 200;101:403-8.

4. Tong $D$, Russell $A H$, Dawson $L E$, et al. Adenocarcinoma of the cecum: natural history and clinical patterns of recurrence following radical surgery. Int J Radiat Oncol Biol Phys 
1983:9:357-60.

5. Willett C, Tepper JE, Cohen A, Orlow E, Welch C, Donaldson $G$. Local failure following curative resection of colonic adenocarcinoma. Int J Radiat Oncol Biol Phys 1984;10:645-51.

6. Mendenhall WM, Rout WR, Lind DS, et al. Role of radiation therapy in the treatment of resectable rectal adenocarcinoma. J Surg Oncol 2002;79:107-17.

7. Mendenhall WM, Zlotecki RA, Snead FE, et al. Radiotherapy in the treatment of resectable rectal adenocarcinoma. Am J Clin Oncol 2009;32:629-38.

8. Kavanagh BD, Pan CC, Dawson LA, et al. Radiation dosevolume effects in the stomach and small bowel. Int J Radiat Oncol Biol Phys 2010;76(3 Suppl):S101-7.

9. Shehata WM, Meyer RL, Jazy FK, Cormier WJ, Welling RE. Regional adjuvant irradiation for adenocarcinoma of the cecum. Int J Radiat Oncol Biol Phys 1987;13:843-6.

10. Kopelson G. Adjuvant postoperative radiation therapy for colorectal carcinoma above the peritoneal reflection. II. Antimesenteric wall ascending and descending colon and cecum. Cancer 1983;52:633-6.

11. Edge SB, Compton CC. The American Joint Committee on Cancer: the 7th edition of the AJCC cancer staging manual and the future of TNM. Ann Surg Oncol 2010;17:1471-4.

12. Cai $B$, Wang MY, Liao $K$, et al. Distribution characteristics of 3,369 Chinese colorectal cancer patients for gender, age, location and tumor size during colonoscopy. Asian Pac J Cancer Prev 2014;15:8951-5.

13. Gonzalez EC, Roetzheim RG, Ferrante JM, Campbell R. Predictors of proximal vs. distal colorectal cancers. Dis Colon Rectum 2001;44:251-8.

14. Slattery ML, Friedman GD, Potter JD, Edwards S, Caan BJ, Samowitz W. A description of age, sex, and site distributions of colon carcinoma in three geographic areas. Cancer 1996;78:1666-70.

15. Nelson RL, Dollear T, Freels $S$, Persky $V$. The relation of age, race, and gender to the subsite location of colorectal carcinoma. Cancer 1997;80:193-7.

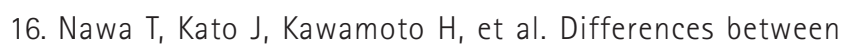
right- and left-sided colon cancer in patient characteristics, cancer morphology and histology. J Gastroenterol Hepatol 2008;23:418-23.

17. Wong CS, Harwood AR, Cummings BJ, Keane TJ, Thomas GM,
Rider WD. Postoperative local abdominal irradiation for cancer of the colon above the peritoneal reflection. Int J Radiat Oncol Biol Phys 1985;11:2067-71.

18. Willett CG, Fung CY, Kaufman DS, Efird J, Shellito PC Postoperative radiation therapy for high-risk colon carcinoma. J Clin Oncol 1993;11:1112-7.

19. Amos EH, Mendenhall WM, McCarty PJ, et al. Postoperative radiotherapy for locally advanced colon cancer. Ann Surg Oncol 1996:3:431-6.

20. Niloofar A, Mosalaei A, Shapour O, Mohammadianpanah M. Role of external irradiation in high-risk resected colon cancer Indian J Cancer 2005;42:133-7.

21. Martenson JA Jr, Willett CG, Sargent DJ, et al. Phase III study of adjuvant chemotherapy and radiation therapy compared with chemotherapy alone in the surgical adjuvant treatment of colon cancer: results of Intergroup protocol 0130. J Clin Oncol 2004;22:3277-83.

22. Ben-Josef $E$, Court WS. Whole abdominal radiotherapy and concomitant 5-fluorouracil as adjuvant therapy in advanced colon cancer. Dis Colon Rectum 1995;38:1088-92.

23. Wong CS, Harwood AR, Cummings BJ, Keane TJ, Thomas GM, Rider WD. Total abdominal irradiation for cancer of the colon. Radiother Oncol 1984;2:209-14.

24. Fabian C, Giri S, Estes $N$, et al. Adjuvant continuous infusion 5-FU, whole-abdominal radiation, and tumor bed boost in high-risk stage III colon carcinoma: a Southwest Oncology Group Pilot study. Int J Radiat Oncol Biol Phys 1995;32:45764.

25. Kuebler JP, Wieand HS, O'Connell MJ, et al. Oxaliplatin combined with weekly bolus fluorouracil and leucovorin as surgical adjuvant chemotherapy for stage II and III colon cancer: results from NSABP C-07. J Clin Oncol 2007;25:2198204.

26. Andre T, Boni $C$, Navarro $M$, et al. Improved overall survival with oxaliplatin, fluorouracil, and leucovorin as adjuvant treatment in stage II or III colon cancer in the MOSAIC trial. J Clin Oncol 2009;27:3109-16.

27. Ludmir EB, Arya R, Wu Y, Palta M, Willett CG, Czito BG. Role of adjuvant radiotherapy in locally advanced colonic carcinoma in the modern chemotherapy era. Ann Surg Oncol 2016;23:856-62. 